\title{
A INCORPORAÇÃO DE DRONES PARA VIGILÂNCIA DE ESPAÇOS URBANOS BRASILEIROS: O USO PELAS FORÇAS ARMADAS E ÓRGÃOS DE SEGURANÇA PÚBLICA DA UNIÃO E DO ESTADO DE SANTA CATARINA
}

\author{
Eduardo Baldissera Carvalho Salles*
}

RESUMO: Com o objetivo de verificar se as Forças Armadas e os órgãos de segurança pública brasileiros têm empregado drones para vigilância de espaços urbanos, desenvolve-se pesquisa empírica, mediante solicitação de acesso à informação aos respectivos entes federativos. Adotase como hipótese que a utilização de novas tecnologias para vigilância coincide com a Copa do Mundo de 2014. Conclui-se com a confirmação da hipótese e que a utilização de drones para tais finalidades naturaliza a violência e transforma o espaço urbano em ambiente de guerra permanente, onde todos são "inimigos" potenciais.

Palavras-chave: Drones; Vigilância; Segurança Pública.

\section{THE INCORPORATION OF DRONES FOR SURVEILLANCE OF BRAZILIAN URBAN SPACES: THE USE BY THE ARMED FORCES AND PUBLIC SECURITY ORGANS OF THE UNION AND THE STATE OF SANTA CATARINA}

\begin{abstract}
In order to verify that the Armed Forces and the Brazilian public security organs have employed drones for surveillance urban spaces, it develops empirical research upon request for access to information to the respective federal entities. It adopts the hypothesis that the use of new technologies for surveillance coincides with the World Cup 2014. It is concluded with the confirmation of the hypothesis and the use of drones for such purposes naturalizes violence and transforms the urban space environment permanent war, where all are potential "enemies".
\end{abstract}

Keywords: Drones; Surveillance; Public Security.

\footnotetext{
Doutorando em Ciências Criminais (PUCRS, Porto Alegre, RS, Brasil). Mestre e Bacharel em Direito (UNOCHAPECÓ, Chapecó, SC, Brasil). Advogado. Rua Rui Barbosa, 119 E, Sala A, Centro, Chapecó, Santa Catarina, Brasil. CEP: 89801-040. E-mail: eduardo@carvalhosalles.com.br
} 


\section{INTRODUÇÃO}

Os drones vêm sendo utilizados em batalhas e guerras pelo menos desde as invasões norte-americanas do Iraque e Afeganistão, sendo de amplo conhecimento o "sucesso" dos equipamentos nas missões para preservação das vidas dos soldados e combatentes por meio do seu emprego em atividades de inteligência, reconhecimento, localização e destruição de alvos com o uso de armamento embarcado.

De acordo com o Mark Neocleous, o Departamento de Defesa dos EUA aumentou a quantidade de veículos aéreos não tripulados de 167 em 2002 para 7000 em 2010; a vigilância de áreas do Iraque, Afeganistão, Paquistão e Iêmen aumentou $1.431 \%$ entre 2001 e 2008 devido a utilização dessas ferramentas aéreas; e ao mesmo tempo tornou-se mais comum a veiculação de notícias jornalísticas sobre o emprego de veículos aéreos não tripulados pelos Estados, os quais reduzem despesas relacionadas com o emprego de recursos humanos para operações militares e, como consequência, eles se tornaram alvo de mobilização política e reflexão por ativistas e pensadores de perspectiva crítica (NEOCLEOUS, 2013, p. 588).

Conforme a tecnologia tornou-se mais acessível, os drones também foram adequados pela indústria para auxiliar em tarefas de monitoramento ambiental, rastreamento de gado e vida selvagem, medição de fenômenos meteorológicos e geofísicos e observação de construções, tais como edifícios e redes de distribuição de energia elétrica, água e gás. Com a abrangência, a redução de custos e a facilidade de operar os veículos aéreos não tripulados, equipes de salvamento alegadamente possuem mais chances de localizar e auxiliar pessoas perdidas em matas ou outros locais inóspitos.

Contudo, essa ferramenta tecnológica também tem sido utilizada domesticamente e por órgãos de segurança pública para atividades de vigilância, investigação e de policiamento ostensivo em localidades de difícil ou perigoso acesso, assim como milícias e outros grupos criminosos também têm feito uso dos equipamentos para monitoramento das áreas de acesso às suas regiões de dominação, investigação dos costumes de seus desafetos e para entrega de drogas em pátios de cárceres. Ante a versatilidade dos drones, parece um truísmo afirmar que as atividades de inteligência e contra inteligência atualmente desempenhadas por atores estatais e não estatais têm feito uso de veículos aéreos não tripulados, podendo extrair-se do cotidiano exemplos citáveis para ilustração, como ações policiais para investigação e prisão de traficantes 
em favelas e entregas de celulares em prisões, facilmente localizáveis em reportagens jornalísticas.

Por isso a análise desenvolvida não acusa os drones como sendo produtos da maldade humana ou instrumentos de um único senhor visando a dominação global. Assim como é tênue a linha a distinguir medicamentos de venenos, pretende-se entender o fenômeno em todas as suas particularidades, sem prejuízo da criticidade.

O drone trata-se, pois, de um artefato aperfeiçoado nos últimos movimentos tecnológicos e inventado no contexto da terceira revolução da tecnologia bélica, a qual sucedeu o uso da pólvora e a fissão nuclear, e cuja característica primordial é a automação e a informação. Mas não só isso. Assim como Foucault e Bourdieu promoviam reflexões sobre questões tradicionalmente estranhas à filosofia para efetivamente despi-las, quer-se aqui não apenas exibir dados concretos sobre o uso de veículos aéreos não tripulados no Brasil, mas também enfrentar os efeitos da ressignificação de valores sociais e filosóficos atrelados ao uso desses equipamentos (CHAMAYOU, 2015).

Como os drones têm capacidade de "projetar poder sem projetar vulnerabilidade" em um nível sem paradigma histórico, o seu uso bélico evidencia as relações assimétricas dos “conflitos" contemporâneos, circunstância que já vinha sendo perceptível pelo menos desde a Guerra do Vietnã, mas que agora é substituída por uma unilateralidade plena, onde o combate dá lugar à caça, e os inimigos são abatidos. Segundo Chamayou, isso permite a eliminação absoluta e radical de qualquer relação de reciprocidade, dá novo significante à noção de guerra e causa ao operador um "esquecimento pragmático", ou seja, pode-se conviver com a família e, nos intervalos, operar um videogame de matar e explodir (CHAMAYOU, 2015, p. 20).

Também causa agravamento da erosão do conceito de Estado-nação, porquanto grande parte desses equipamentos não são apenas produzidos por corporações transnacionais privadas, mas também são integralmente operados por empresas militares com operações em diversas partes do globo, as quais não respeitam as linhas imaginárias dos mapas, que contemporaneamente mais servem de ilustração para melhor significação da política do que impedem a transposição dos territórios pelos drones e outros itens universalizáveis pelo neoliberalismo, como bens de consumo e a financeirização.

Por isso, sem olvidar do uso comum e crescente por outros atores, com as mais diversas finalidades, a pesquisa limita-se a questionar a legitimidade, os limites e riscos decorrentes do 
uso dos veículos aéreos não tripulados por órgãos de segurança pública brasileiros em operações envolvendo civis em áreas urbanas.

Assim, em abril de 2018 iniciou-se pesquisa empírica por meio da coleta de informações sobre a quantidade e a finalidade dos equipamentos adquiridos pelos Estados e a União desde o ano de 2013. Quanto aos reflexos desse fenômeno na sociedade, no mesmo período iniciouse a realização de pesquisa bibliográfica sob o método dedutivo, adotando-se a hipótese (provisória) de que após a realização da Copa do Mundo de 2014 houve um aumento do número de veículos aéreos não tripulados no país adquiridos pelos órgãos investigados, inexistindo regulação ou política pública clara sobre o uso.

Tratando-se de pesquisa de longa duração e com a participação de outros pesquisadores, momentaneamente é possível apresentar apenas impressões preliminares a partir dos dados até agora coletados, e, por essa razão, o presente trabalho não esgotará o objeto investigado, mas apresentará a comunidade científica apenas as impressões provisórias extraídas neste estágio da análise, limitando-se a abordar empiricamente os dados concernentes à União e ao Estado de Santa Catarina, porquanto vários entes federativos cercearam o acesso à informação invocando "razões de Estado" ou ainda não responderam os requerimentos formulados. Conforme a pesquisa for sendo desenvolvida, espera-se complementar os estudos mediante a divulgação de novos artigos com outras informações relevantes e inéditas sobre o uso de drones no Brasil.

Nesse contexto, o primeiro ponto a ser abordado no presente artigo é o conceito de veículo aéreo não tripulado (VANT) e drone, apontando-se as características comuns a esses equipamentos e as razões que motivaram a adoção da terminologia drone em detrimento de outras também comuns no léxico acadêmico.

Na sequência, apresenta-se os resultados parciais da pesquisa empírica desenvolvida, elaborando-se interpretações fenomenológicas acerca dos dados coletados junto à União e o Estado de Santa Catarina para, em seguida, apresentar considerações provisórias a respeito do panorama fático verificado.

Por fim, elabora-se narrativa refletindo sobre os possíveis problemas relacionados com o uso dos equipamentos, que invariavelmente causam a desumanização e despolitização dos alvos para justificar a perpétua exposição à vigilância, inexistindo alternativas regulatórias viáveis para estancar ou amenizar ou eventuais efeitos sociais. 


\section{ANÁLISE PRELIMINAR SOBRE O USO DE DRONES NO BRASIL}

\subsection{O Que São Drones?}

Os veículos aéreos não tripulados também são denominados drones, “aeronaves sem piloto", "veículos remotamente pilotados", "sistema de aeronave remotamente pilotada", e em inglês, "Unmanned Aerial Vehicles (UAVs)" (CLARKE, 2014, pp. 247-262). Essa gama de termos pode se referir a espécies de aeronaves distintas, como aquelas de uso doméstico até mesmo aquelas empregadas pelas forças militares em operações. Contudo, dentro do presente artigo todas elas serão denominadas drones, e devem ser entendidas como qualquer aeronave cuja intervenção humana para o seu funcionamento pode ser exclusivamente exterior, ou seja, equipamentos aéreos que não exigem piloto embarcado para serem controladas.

Não se desconhece, por outro lado, a existência de veículos não tripulados terrestres e aquáticos, também denominados pelo termo drone. Contudo, como o presente trabalho limitase ao estudo dos equipamentos aéreos, para evitar equívocos terminológicos, faz-se o referido esclarecimento para justificar a adoção do termo.

Os possíveis benefícios e malefícios causados por esses equipamentos estão diretamente relacionados com suas capacidades operacionais e características físicas. Devido ao aperfeiçoamento dos recursos informacionais e tecnológicos, combinando-se a transmissão de dados em velocidades cada vez mais rápidas, já é possível controlar veículos aéreos não tripulados por satélites e até mesmo dispensar o reabastecimento de combustível devido a utilização de energia solar, que potencialmente permite o uso desses equipamentos por muitos anos, sem pouso, e de maneira quase imperceptível aos humanos, afinal, frente aos aviões tripulados, os drones provocam muitíssimo menos ruído e são mais flexíveis quanto ao tamanho e altitude.

Originalmente construídos para missões de reconhecimento e vigilância, sabe-se que os veículos aéreos não tripulados também estão sendo empregados atualmente para identificar (e realizar) contaminação química, biológica, radiológica, nuclear e explosiva, reabastecer outras aeronaves, retransmitir sinais telemáticos, estudar o espaço sideral, mapear e monitorar ecossistemas, controlar a quantidade de poluentes no ar, prevenir e planejar a ocorrência de catástrofes climáticas, gerir gasodutos, detectar e vigiar incêndios florestais, pulverizar agrotóxicos e acompanhar o estado das culturas agrícolas, entre outros usos domésticos (CLARKE, 2014, pp. 230-246). 
Os drones podem ser equipados com radares e sensores de imagens térmicas e digitais, os quais são eficazes para executar vigilância noturna e observação de seres humanos em qualquer ambiente, revelando desde esconderijos e túneis à detalhes de edificações e residências urbanas. Quando essas ferramentas militares passam a estar disponíveis para atores estatais utilizarem em contextos civis, torna-se recorrente a violação ao direito à privacidade, sobretudo quando os dados coletados através das paredes permitem extrair padrões sexuais, alimentares e de sono, devassando a intimidade da pessoa observada de uma maneira absolutamente paradigmática.

O uso de equipamentos para monitoramento cresceu sensivelmente após a Guerra do Iraque. No contex to do conflito, em 2007 o exército norte-americano criou e empregou um sistema denominado "Angel Fire", cuja função era vigiar a partir do céu os iraquianos e, após a ocorrência de algum fato relevante - como um ataque a um comboio de veículos militares -, oferecer imagens de maneira retroativa, como uma espécie de fita de vídeo sendo rebobinada, para que os militares desvendassem o caminho feito pelos inimigos antes e após o ataque, e, assim, descobrissem os seus esconderijos de armas, explosivos e pessoas. O sistema funcionava por meio de câmeras acopladas em uma aeronave que permanecia sobrevoando em círculos uma área de sessenta e cinco quilômetros quadrados. As câmeras faziam milhares de fotografias que, depois, eram unidas. Assim os militares norte-americanos podiam retroceder, avançar, aproximar e identificar pessoas e veículos, obtendo informações e aperfeiçoando as atividades de inteligência para desbaratar os inimigos (GLOBAL SECURITY, 2018). Esse sistema foi aperfeiçoado e implantado pela empresa norte-americana "Persistent Surveillance Systems" em Juárez, Filadélfia, Compton, Indianápolis, Columbus, Cleveland e Nogales, nos EUA, além de Mexicali e Torreón, no México. Em seu site é possível acessar gravações de imagens aéreas dessas cidades, onde alegadamente o sistema foi utilizado por órgãos policiais com sucesso para desvendar a autoria de crimes (PERSISTENT SURVEILLANCE SYSTEMS, 2018). Com a veiculação de trechos dessas imagens aéreas na internet, o debate em torno do direito à privacidade passa necessariamente por questões como o uso e o acesso indevido às imagens, bem como a legitimidade na coleta dessas informações.

Ao mesmo tempo, o crescente uso doméstico desses equipamentos torna a questão ainda mais complexa, já que os próprios drones estão à disposição das pessoas para qualquer finalidade, desde o desenvolvimento da ciência, indústria e comércio, à prática de espionagem e o cometimento de crimes, provocando debates em torno de alternativas para proteção do 
direito à privacidade. As discussões acadêmicas contemporâneas geralmente apontam a suposta imprecisão do direito à privacidade, a dificuldade de apurar os malefícios e os benefícios dos drones (CLARKE, 2014, pp. 286-305), e a incapacidade ou insuficiência do direito na criação de ferramentas adequadas e efetivas para redução dos riscos sem causar empecilhos ao uso equilibrado da tecnologia (VOLOVELSKY, 2014, pp. 306-320). Isso porque, argumenta-se que a regulação jurídica tende a falhar porque torna-se impossível impedir que o operador do equipamento deixe de observar determinada conduta relativa à esfera íntima da pessoa submetida aos avançadíssimos sensores e câmeras (CLARKE, 2014, pp. 263-285).

Em um contexto onde não há espaço seguro onde o ser humano possa estar sem sujeitarse a exposição a câmeras de vídeo, a vigilância tornou-se permanente e irrestrita, e ultrapassam os simples circuitos internos de TV. O céu passa a estar repleto de olhos eletrônicos e onipresentes, dando contornos relevantes e urgentes a esse debate acerca da colisão do direito à privacidade e a presunção de inocência frente a complexificação de um sistema orwelliano de vigilância cujo Big Brother não se origina numa opressão ditatorial e maniqueísta do Estado em desfavor dos seres humanos, mas é realizada por uma miríade de atores estatais e não estatais, incluindo aí outros Estados, corporações transnacionais, organizações não governamentais e organizações terroristas, por exemplo.

Dessa forma, passa-se a perscrutar os resultados parciais da pesquisa empírica desenvolvida sobre a quantidade de drones adquiridos pela União e pelo Estado de Santa Catarina, elaborando-se interpretações acerca dos dados coletados para, em seguida, apresentar uma conclusão a respeito do panorama brasileiro.

\subsection{O Acervo de Drones da União e do Estado de Santa Catarina}

A partir do mês de abril de 2018 tem sido realizada em conjunto com outros pesquisadores brasileiros uma investigação por meio da coleta de informações sobre a quantidade e a finalidade dos drones adquiridos pelos Estados federados e a União desde o ano de 2013. Para tanto, apresentou-se aos Serviços de Informação ao Cidadão (SIC) pedidos de acesso à informação pertinente à administração do patrimônio público e a utilização de recursos e bens dos Estados e da União.

Os requerimentos foram apresentados com identificação pessoal do pesquisador, contudo, os órgãos não foram informados sobre os motivos determinantes das solicitações.

Rev. de Direito, Governança e Novas Tecnologias | e-ISSN: 2526-0049 | Porto Alegre | v. 4 | n. 2 | p. 83 - 103 | Jul/Dez. 2018 
Como vários entes ainda não responderam os requerimentos formulados e diante da grande quantidade de dados a serem apresentados, este artigo limita-se a abordar empiricamente os dados concernentes à União e ao Estado de Santa Catarina.

Por meio do Sistema Eletrônico do Sistema de Informação ao Cidadão (eSIC) da Controladoria Geral da União (BRASIL, 2018) foram apresentados pedidos de acesso à informação aos Comandos do Exército, da Marinha e da Aeronáutica, ao Departamento de Polícia Federal e ao Departamento de Polícia Rodoviária Federal. Pela Ouvidoria Geral do Estado de Santa Catarina (ESTADO DE SANTA CATARINA, 2018) requereu-se informações à Polícia Militar, à Polícia Civil e ao Corpo de Bombeiros Militar.

Em síntese, foi requerido: (a) o número de veículos aéreos não tripulados (VANT/DRONE) adquiridos de 2013 a 2018; (b) indicação dos atos administrativos que justificaram/motivaram a aquisição de veículos aéreos não tripulados (VANT/DRONE) de 2013 a 2018; (c) relação dos modelos, fabricantes e preços de veículos aéreos não tripulados (VANT/DRONE) adquiridos de 2013 a 2018; (d) relação discriminada do número de veículos aéreos não tripulados (VANT/DRONE) disponíveis para uso.

O Comando do Exército demorou 22 dias para apresentar as informações. O órgão afirmou ter adquirido 94 drones a partir do ano de 2014, que as aquisições foram fundadas nas “Condicionantes Doutrinárias e Operacionais" e na "Diretriz de Coordenação para Obtenção", e que os drones são denominados pelo Exército brasileiro como "Sistemas de Aeronaves Remotamente Pilotadas" (COMANDO DO EXÉRCITO, 2018).

Extrai-se da "Diretriz de Coordenação para a Obtenção dos Sistemas de Aeronaves Remotamente Pilotadas", que o uso de drones pelo Exército brasileiro tem por objetivo “assegurar a liberdade de ação e aumentar o nível de consciência situacional dos comandantes, possibilitando a preservação dos recursos humanos, em situações nas quais o risco seja elevado ou inaceitável e em missões que possam imprimir excessivo desgaste às tripulações das aeronaves pilotadas" (BRASIL, 2014). No referido documento não há menção sobre o emprego de aeronaves remotamente controladas em áreas urbanas ou em operações envolvendo civis. Contudo, soube-se por meio das informações apresentadas pelos outros órgãos da União - a seguir mencionadas - que os equipamentos do Exército brasileiro também foram empregados em operações conjuntas em contextos civis. 


\section{A INCORPORAÇÃO DE DRONES PARA VIGILÂNCIA DE ESPAÇOS URBANOS BRASILEIROS: O \\ USO PELAS FORÇAS ARMADAS E ÓRGÃOS DE SEGURANÇA PÚBLICA DA UNIÃO E DO \\ ESTADO DE SANTA CATARINA}

Não se sabe se o órgão possui regulação interna sobre o uso e divulgação de informações íntimas eventualmente colhidas de civis, ou se realizou estudo sobre o sucesso de operações em áreas urbanas onde os drones foram empregados.

Por outro lado, o Comando da Marinha demorou 18 dias para responder a solicitação e esclareceu ter adquirido 4 drones. As aquisições ocorreram em 2016 e 2017, sendo que o primeiro equipamento serviu para atender a necessidade de "estrutura de vigilância e proteção de alta complexidade e eficácia" demandado pelos "Jogos Olímpicos e Paralímpicos Rio 2016", enquanto os demais foram necessários para execução das ações de "Garantia da Lei e da Ordem (GLO) autorizadas por decreto da Presidência da República em julho de 2017, com a atuação de tropas das Forças Armadas na segurança pública no Estado do Rio de Janeiro” os quais foram empregados "nas operações em áreas urbanas, como equipamento necessário para o levantamento de dados de inteligência e vigilância dos locais onde as tropas de Fuzileiros Navais iriam atuar" (COMANDO DA MARINHA, 2018).

Até o momento o Comando da Marinha não informou a existência de ato normativo regulando ou instruindo o uso desses equipamentos em contextos civis.

O Comando da Aeronáutica respondeu o pedido após 21 dias, tendo informado que "no período de 2013 a 2018 foi adquirida uma aeronave remotamente pilotada, modelo Hermes 900, fabricada pela Elbit, no valor de US\$ 8.000.000,00 (oito milhões de dólares americanos), tendo como atos motivadores para sua aquisição seu emprego no desenvolvimento de doutrina de operação, coleta e fornecimento de imageamento e inteligência de sinais" (COMANDO DA AERONÁUTICA, 2018). Apesar de não ter prestado esse esclarecimento, a Força Aérea Brasileira divulgou na imprensa ter adquirido a referida aeronave para ser empregada em operações relacionadas com a Copa do Mundo de 2014, a qual conta com "um conjunto de 10 câmeras de alta resolução que permitem a vigilância de uma região inteira" (FORÇA AÉREA BRASILEIRA, 2014).

Também não houve esclarecimentos quanto a ato normativo especificando regras ou instruções a serem observados pelos militares na operação de veículos aéreos não tripulados em operações envolvendo civis.

O Departamento de Polícia Federal é o único órgão da União que não atendeu o pedido de fornecimento das informações. Assim, apresentou-se reclamação ao Ministério da Justiça informando o esgotamento do prazo para resposta. No requerimento foi salientado que o pedido se refere a informações gerais e abstratas acerca de patrimônio público posto à disposição do 
órgão, e não afeta o sucesso de nenhuma operação de segurança eventualmente em andamento, tendo as Forças Armadas deferido pedido análogo. Contudo, em 7 de junho de 2018 o pedido de acesso foi indeferido por tratem-se de "informações classificadas", as quais abrangem “informação econômica ou informação científico-tecnológica cuja divulgação implique risco ou dano aos interesses da sociedade e do Estado" (DEPARTAMENTO DE POLÍCIA FEDERAL, 2018).

Invocar "razões de Estado" para cercear informações sobre o uso de drones em atividades militares é prática comum em outros países. Conforme revelado pelo Wikileaks, o governo norte-americano reiteradamente tentou evitar a divulgação de vídeos de militares atacando indiscriminadamente civis iraquianos, ocorrências consideradas violadoras de direitos humanos (WIKILEAKS, 2018).

Por outro lado, o Departamento de Polícia Rodoviária Federal demorou 29 (vinte e nove dias) para apresentar resposta ao pleito, tendo informado que "a PRF está em processo de implantação das atividades com RPAs (aeronaves remotamente pilotadas)" e que "recentemente foi elaborado o primeiro manual de operações e que ainda aguarda sua publicação para entrar em vigor". Quanto ao número de equipamentos, o órgão disse que "as atividades até então exercidas dentro da instituição, foram realizadas por iniciativas isoladas, algumas relatadas oficialmente e outras sem informações até o presente". O órgão informou não dispor do quantitativo exato em uso, mas assinalou que "a grande maioria foi doada pela Receita Federal com o intuito de testar em operações de fiscalização de trânsito, monitoramento de rodovias, controle de fluxo, treinamento de servidores e utilização em grandes eventos como Copa do Mundo e Olimpíadas" (DEPARTAMENTO DE POLÍCIA RODOVIÁRIA FEDERAL, 2018).

A Polícia Rodoviária Federal é quem, aparentemente, mais tem empregado os veículos aéreos não tripulados em áreas urbanas, notadamente para execução das suas atribuições e competências legais relacionadas com o policiamento de rodovias federais. Não foi localizado no Diário Oficial da União o citado "manual de operações”, contudo, o dado mostra inclinação do órgão para controlar o uso dos referidos equipamentos.

O Estado de Santa Catarina respondeu o pedido com tabela constando o mês de aquisição, a localização, o modelo, os acessórios, o valor total do investimento e a fonte do recurso. Também foi reconhecida a inexistência de norma interna regulando a aquisição e uso desses equipamentos e que "as unidades da PMSC utilizam o equipamento para ações de 
inteligência" - sugerindo que o órgão excede suas atribuições empregando os drones para investigação de civis (ESTADO DE SANTA CATARINA, 2018).

Quanto a Polícia Militar e Polícia Militar Ambiental, em junho de 2018 existiam 28 equipamentos distribuídos em grande número de unidades militares localizadas em todas as regiões do Estado. Quanto ao Corpo de Bombeiros, nota-se que o primeiro drone foi adquirido em janeiro de 2017, sendo que em junho de 2018 o acervo possuía 14 unidades distribuídas em todas as regiões da unidade federativa. O ente adquiu apenas 5 (cinco) equipamentos, tendo os outros 9 (nove) drones lhes sido doados pela comunidade ou outros entes ou órgãos, como Municípios, Receita Federal e Justiça Federal. Apesar de não ter sido informada a existência de regulação do uso dos equipamentos, segundo o Corpo de Bombeiros Militar, "além de resguardar, em muitas situações, a integridade física dos próprios bombeiros, os drones, com um custo operacional baixo quando comparado a outros equipamentos, permitem acessar e visualizar com agilidade as áreas de difícil acesso" (ESTADO DE SANTA CATARINA, 2018).

Como o ente não informou a existência de equipamentos à disposição da Polícia Civil, existindo relatos do emprego de drones pelos policiais catarinenses desde 2013 (PAULUS, 2013), apresentou-se recurso requerendo a complementação das informações. Contudo, até o presente momento não houve resposta ao recurso.

As informações coletadas estão esquematizadas nos seguintes quadros:

Quadro 1 - Quantidade de drones de órgãos da União

\begin{tabular}{|c|c|c|c|c|}
\hline \multicolumn{5}{|c|}{ Órgãos da União } \\
\hline Exército & Marinha & Aeronáutica & Polícia Rodoviária Federal & Polícia Federal \\
\hline 94 & 4 & 1 & Não sabe & Informação classificada \\
\hline
\end{tabular}

Fonte: O autor (2018).

Quadro 2 - Quantidade de drones de órgãos do Estado de Santa Catarina

\begin{tabular}{|c|c|c|c|}
\hline \multicolumn{4}{|c|}{ Órgãos do Estado de Santa Catarina } \\
\hline Polícia Militar & Polícia Militar Ambiental & Polícia Civil & Corpo de Bombeiros \\
\hline 27 & 1 & Não respondeu & 14 \\
\hline
\end{tabular}

Fonte: $\mathrm{O}$ autor (2018).

Rev. de Direito, Governança e Novas Tecnologias | e-ISSN: 2526-0049 | Porto Alegre | v. 4 | n. 2 | p. 83 - 103 | Jul/Dez. 2018 
A partir das informações coletadas observou-se sensível tendência das Forças Armadas brasileiras e dos órgãos de segurança pública de Santa Catarina em inserirem aeronaves não tripuladas em suas operações e missões. Todas as aquisições ocorreram após 2013, confirmando a hipótese inicialmente aventada de que os grandes eventos ocorridos no país - Copa do Mundo e Olimpíadas - provocaram o aumento dos esforços dos órgãos de segurança para incorporação de novas tecnologias.

Também chama a atenção a existência de considerável número de aeronaves com os órgãos do Estado de Santa Catarina, notadamente a Polícia Militar, a qual, devido à grande quantidade de equipamentos, aparentemente tem empregado os drones para o exercício das funções de polícia judiciária e a apuração de infrações penais comuns.

Contudo, como o presente trabalho interessa-se pelas implicações que o emprego dessa tecnologia de distanciamento, ou de transferência do risco, pode provocar em âmbitos tão importantes como a segurança pública, no próximo tópico conjuga-se as informações antes expostas com uma breve análise da contemporaneidade.

\subsection{As Consequências e Desafios do Uso de Drones}

A história está repleta de "vencedores" e "vencidos", "ganhadores" e "perdedores", "vitoriosos" e "derrotados". Adotando-se uma perspectiva benjaminiana de enxergar os fatos, é inadmissível ser a história contada como uma acumulação linear, irrefreável e atemporal de conquistas humanas. Há muitos mortos pelo caminho, e eles devem ser ressuscitados para contar a sua história. Olhar para os acontecimentos sem ver as sarjetas e os cemitérios causa a equivocada e simples reprodução do discurso vencedor, invariavelmente contaminado pelos interesses de seu próprio grupo. Por isso os cadáveres da história não devem ser encarados como acidentes naturais como rios e montanhas, mas são importantes pontos de partida para a análise dos fatos (MATE, 2011).

Daí porque deve-se adotar conduta epistemológica que se encarregue de expor a história da pessoa vitimada para, a partir dela, reconstruir a história no presente. Neste caso, é imprescindível ao leitor enxergar os efeitos dos drones da perspectiva das vítimas.

O século XX pode ser abordado de vários ângulos. O desenvolvimento da tecnologia da informação e de ferramentas de transporte mais eficientes são, sem dúvidas, elementos chave nesse período, porquanto o aperfeiçoamento desses mecanismos permitiu a transposição 
maneira cada vez mais rápida de distâncias antes intransponíveis e, consequentemente, tem colocado em xeque a noção de fronteiras nacionais (SALLES, 2018). Essas abordagens geralmente partem do tema "globalização", com todos os seus nuances e críticas, e devem ser consideradas quando se pretende analisar a contemporaneidade.

Embora Hobsbawn utilizasse o termo "era dos extremos" (HOBSBAWN, 1995) para caracterizar o século passado, essa designação também serve para denominar os tempos atuais, afinal, a impessoalidade que caracterizava as batalhas da Guerra do Vietnã agora tornou-se regra. A emergência dos veículos aéreos não tripulados ocorre em um contexto cada vez mais acelerado de virtualização da vida e destruição dos aspectos da responsabilidade humana, ou, dito em outras palavras, em um ambiente onde a tecnologia transforma tudo em abstrato, em imaterial, aliviando a carga da decisão para garantir uma boa-noite de sono a todos.

Isso não é verificável apenas na guerra ou em conflitos urbanos, mas no cotidiano, quando o magistrado julga processos eletrônicos sem jamais ter conhecido pessoalmente os advogados, as partes ou as testemunhas, ou então quando o professor ensina e avalia milhares de estudantes pela internet, limitado apenas às informações que lhe são fornecidas pelo sistema. A tecnologia permite a evisceração remota de alguém que o julgador jamais viu, e jamais verá, transformando assim tudo em virtual, em potencial, aliviando a responsabilidade da decisão.

Sem contar, é claro, na possibilidade de redução gradual de parte do controle e da decisão humana no funcionamento dos drones, o que, na prática, representa a passagem da "autonomia supervisionada" para uma autonomia total dos robôs, possibilidade já admitida pelo Departamento de Defesa norte-americano e em fase de pesquisa pelo roboticista Ronald Arkin (CHAMAYOU, 2015, p. 229). O surgimento de drones autônomos colocaria em xeque a ideia de responsabilidade e várias outras categorias jurídicas, representando uma crise radical na aplicabilidade do direito, afinal, se um robô cometesse um crime quem seria o responsável? (CHAMAYOU, 2015, p. 232).

Para Hobsbawn (HOBSBAWN, 1995), as maiores crueldades e catástrofes do século XX tiveram origem na impessoalização das decisões, isto é, desastres humanitários como o holocausto só foram possíveis devido a tecnificação e a objetificação das pessoas, em um ambiente permeado pela burocracia e divisão de tarefas. Ao invés de termos esperanças em dias melhores, os incipientes passos deste novo século sugerem que as ações humanas possuem muita semelhança com as do período histórico anterior, afinal, o emprego de drones desumaniza o alvo e ilide a responsabilidade do operador. 
Portanto, pode-se dizer que os veículos aéreos não tripulados foram importados das zonas de guerra e já sobrevoam áreas urbanas, sendo empregados para auxiliar atividades policiais e de emergência, inclusive no Brasil. Existem dados empíricos corroborando a assertiva e vários estudos acadêmicos de cunho social e filosófico vem sendo publicados com esse argumento, notadamente os de Grégoire Chamayou (2015), Stephen Graham (2016), Ian Shaw (2016) e Achille Mbembe (2017).

Contudo, o resultado parcial do levantamento realizado mostra que os veículos aéreos não tripulados pertencentes à União e ao Estado de Santa Catarina não são capazes de disparar mísseis e aniquilar vidas humanas mediante o assassinato impessoal e a partir de uma tela de computador; nem mesmo o caríssimo Elbit Hermes 900, adquirido pela Força Aérea Brasileira, que possui diversas câmeras de monitoramento, é capaz desse feito. Os equipamentos utilizados pelo Brasil são, em sua imensa maioria, pequenos e leves, com reduzida capacidade de carga, e empregados apenas para vigilância.

Assim, a crueldade verificável em assassinatos impessoais executados por controle remoto não é "o grande problema" dos veículos aéreos não tripulados, afinal, a tecnologia simplesmente deixa a decisão mais abstrata, maximiza a letalidade e diminui os riscos para uma das partes. Desde o início do século XX já era possível matar de modo impessoal, isto é, determinar a detonação de cidades inteiras mediante rádios e comandos eletrônicos. Nesse aspecto, um "drone" não difere muito dos aviões e helicópteros, porque possuiriam apenas o benefício de dispensarem a necessidade de piloto embarcado.

Essa percepção é compartilhada por Mark Neocleous, para quem os drones em um âmbito global não constituem nova forma de tecnologia militar adaptada para contextos civis, mas uma continuação do poder aéreo exercido pela polícia. Para ele, "a grande maioria dos drones não são sofisticadas máquinas de bombardear ou matar, mas são, na verdade, modelos pequenos e desarmados usados primariamente para vigilância do campo de batalha" (NEOCLEOUS, 2013, p. 589).

Para Neocleous, além dos dados sobre os drones norte-americanos mostrarem a diminuta utilização deles em operações militares com artefatos explosivos, sua função principal não é bombardear ou assassinar, mas construir conhecimento. E desse modo, o autor defende a inexistência de áreas civis ou não civis em um ambiente permeado pelo poder de polícia aéreo, isto é, pela dominação de uma lógica onde a capacidade de captura e aniquilamento de um 
inimigo pode ser executada mais eficientemente pelo ar. Para ele, todos os civis tornaram-se suspeitos de algo e são submetidos a investigações permanentes (NEOCLEOUS, 2013, p. 589).

As corporações fabricantes desses equipamentos naturalizam o seu uso no cotidiano destacando os benefícios para auxiliar em tarefas de buscas e salvamentos, auxílio em desastres, monitoramento e policiamento. A mesma informação é verificada no WYSS Institute, da Harvard University, que justifica o desenvolvimento de "drones" para o emprego nessas atividades (WYSS INSTITUTE, 2018). Assim, os drones são apresentados como espécies de câmeras de vigilância evoluídas, que agora não necessitam de cabos e têm a capacidade de transpor muros e fronteiras. Contudo, esse discurso oculta os interesses econômicos das corporações transnacionais bem como os riscos à privacidade e intimidade, seja pela possibilidade de comercialização dos dados de comportamento individual e coletivo de determinadas regiões, seja pela possibilidade de recrudescimento de políticas de segurança, em que os métodos de policiamento são potencializados rumo a uma sociedade perpetuamente vigiada.

Nesse sentido, o aspecto mais grave e inovador desses equipamentos é a possibilidade de manter um olhar constante sobre o inimigo, e assim, utilizar-se dos "drones" para a vigilância permanente de todas as vidas urbanas. Assim, tais equipamentos podem manter um "olhar persistente ou de vigília permanente", superando as limitações biológicas que o piloto representava para o avião ou helicóptero. Como "o olho mecânico não tem pálpebras", seu funcionamento pode permanecer constante. Além dessa persistência do olhar, a vigilância pode ser total, isto é, o campo de visão é estendido em todas as direções, "com câmeras orientadas em todos os sentidos, como as múltiplas facetas de um olho de mosca" (CHAMAYOU, 2015, p. 48).

A vigilância dos "drones" não se limita ao tempo real, mas se redobra em uma função de gravação e arquivamento de áreas do tamanho de cidades inteiras, para poder seguir os deslocamentos de todas as pessoas após os fatos acontecerem, e de maneira retroativa. Segundo Chamayou, "depois de realizado, esse filme de todas as vidas e de todas as coisas poderia ser repassado milhares de vezes, focalizando cada vez um personagem diferente, aproximando dele para rever a história a partir de sua escala. Seria possível escolher trechos, voltar, rever ou adiantar as cenas" (CHAMAYOU, 2015, p. 49). Com isso, não se navega apenas no espaço, mas também no tempo. 
Outra face inovadora desses equipamentos é a possibilidade de fusão de dados, ou seja, a associação de imagens com interceptações de comunicações eletrônicas emitidas por rádios, celulares e outros dispositivos de dados (CHAMAYOU, 2015, p. 51). Essa ideia está presente quando se associa à interceptação telefônica os dados de localização dos interlocutores e a correspondente gravação de vídeo do local, por exemplo.

A categorização de pessoas em amostras, dados e números é uma característica presente naquilo que pode ser denominado "princípio de esquematização das formas de vida", que consiste na "capacidade de 'visualizar dados provenientes de diversas fontes, combinando o 'onde', o ‘quando' e o 'quem' em um traçado em três dimensões”. Assim, pode-se seguir uma pessoa em diversos âmbitos (rotas de deslocamento, ligações telefônicas, mensagens eletrônicas, afinidades pessoais, redes sociais, religião, preferências alimentares, comportamento online, rotinas de lazer, etc.) para construir um padrão ou um "esquema de vida" baseado nas informações de suas atividades diárias. O objetivo dessa prática é, mais do que seguir eventuais suspeitos determinados, identificar suspeitos em potencial de acordo com a definição de comportamentos pré-fixados (CHAMAYOU, 2015, p. 52).

Tais equipamentos também são teoricamente capazes de detectar anomalias e agir preventivamente mediante o escaneamento de imagens para "identificar, no meio de todas as atividades, os acontecimentos pertinentes", isto é, qualquer comportamento que altere as atividades habituais de determinado local. Essa capacidade premonitória permite o reconhecimento automático de certos cenários visando emitir alertas precoces de ameaça aos seus operadores, como, por exemplo, o eventual esvaziamento repentino e incomum de uma ponte por causa de uma rachadura ou bomba (CHAMAYOU, 2015, p. 53).

Em uma perspectiva foucaultiana essa perpetuidade da suspeita é característica da biopolítica, com a qual o governo é exercido para garantir a vida e tem a prerrogativa de fazer viver e deixar morrer. Em outras palavras, biopolítica possibilita o controle para proteção da vida, da regulação do corpo e da proteção de outras tecnologias, e, nesse contexto, a exposição perpétua à vigilância, ao olho que tudo vê, constitui notável faceta do fenômeno, afinal, os fins da polícia (garantir a segurança) é reiteradamente justificado por si e para si (FOUCAULT, 1978, pp. 277-293). Por outro lado, em uma sociedade onde o saber instrumentaliza o poder, deter informações privilegiadas sobre a conduta de outrem permite a produção de poder, em uma relação de causa e efeito simbiótica onde o conhecimento produz cada vez mais poder, e vice-versa. 
Quanto ao quadro investigado, pode-se dizer provisoriamente que os drones realmente têm sido utilizados para alimentar bancos de dados policiais, que instrumentalizam o saber sobre a vida dos alvos e viabilizam tanto o controle quanto a inserção dos "corpos dóceis" nos processos sociais e econômicos. Muito além da localização de um criminoso, esses equipamentos têm potenciais mais complexos, como o monitoramento perpétuo de comportamento para execução de políticas Minority Report. A própria recusa da Polícia Federal em prestar as informações solicitadas, justificando que a divulgação implicaria risco ou dano aos interesses da sociedade e do Estado, sugere que o emprego de tais equipamentos em atividades de vigilância não é meramente virtual ou discurso apocalíptico, mas pode estar ocorrendo no âmbito das atribuições constitucionais do órgão, que incluem a apuração de infrações penais contra a ordem política e social, por exemplo.

Por outro lado, apesar de supor que as corporações transnacionais também façam uso de drones para suas atividades empresariais, a fluidez, a complexidade e a opacidade de suas estruturas torna a investigação muito difícil, porquanto há intermináveis níveis hierárquicos na maior parte dos atores não estatais, de modo que qualquer argumento penetra em algum de seus intermináveis braços e se perde numa massa desforme, de difícil delimitação e responsabilização, e recheada de funcionários subalternos (SALLES, 2018, p. 165). Essa questão acerca da utilização dos drones por tais atores não estatais é relevante porque as ferramentas que conferem legitimidade política foram construídas na modernidade e não se aplicam às corporações transnacionais, as quais apresentam-se fechadas e não se submetem a controle externo ou transparência administrativa, e poderiam fazer uso de eventuais dados para comercialização ou desenvolvimento de suas atividades orientadas pela economia - como recentemente descoberto no escândalo envolvendo a Cambridge Analytica e o Facebook.

\section{CONSIDERAÇÕES FINAIS}

Assim como a guerra aérea sucedeu a guerra terrestre, a guerra aérea foi substituída pela guerra à distância, a qual baseia-se no conceito de sistema pilotado à distância. Com o surgimento dos drones, o emprego desse equipamento em áreas urbanas evidencia o esvaziamento da ideia de Estado-nação, não apenas porque esses equipamentos são produzidos e operados por corporações transnacionais, mas também servem à milícias e empresas militares 
sediadas em diversas localidades terrestres e cujas atividades não respeitam as fronteiras ilustrativas e ideacionais dos mapas políticas.

A importação dessa tecnologia aos centros urbanos é uma consequência da Guerra ao Terror, quando as indústrias bélicas passaram a desenvolver novos instrumentos para utilização em operações militares e de vigilância em ambientes urbanos. Partindo do pressuposto de que os drones projetam poder sem projetar vulnerabilidade, e sem deixar de considerar o uso comum e crescente desses equipamentos para as mais diversas finalidades da vida humana, desenvolveu-se o presente estudo com o objetivo de analisar a legitimidade, os limites e os riscos decorrentes do uso de drones por órgãos de segurança pública brasileiros em operações envolvendo civis em áreas urbanas.

Como a pesquisa é de longa duração e conta com a participação de outros pesquisadores, neste trabalho optou-se por delimitar a apresentação de resultados parciais e provisórios abrangendo informações sobre a quantidade e a finalidade dos drones adquiridos pela União e o Estado de Santa Catarina a partir do ano de 2013.

Apesar do objeto de estudo se limitar à segurança pública, sabe-se os drones também são potencialmente empregados por corporações transnacionais para a execução de suas atividades comerciais e espionagem industrial. Contudo, devido a opacidade de suas estruturas e a falta de transparência de seus recursos e atividades, os pesquisadores não solicitaram informações ao setor privado, limitando-se ao poder público brasileiro.

No primeiro ponto do artigo, abordou-se o conceito de drone e de veículo aéreo não tripulado (VANT), apontando-se as características comuns a esses equipamentos e as razões que motivaram a adoção da terminologia drone em detrimento de outras também comuns no léxico acadêmico. Na sequência, apresentou-se os resultados parciais da pesquisa empírica desenvolvida, elaborando-se interpretações acerca dos dados coletados para, em seguida, apresentar-se considerações provisórias a respeito do panorama observado. Por fim, elaborouse análise sobre os possíveis problemas relacionados com o uso dos drones na segurança pública, que invariavelmente causam a objetificação e desumanização dos alvos para justificar a perpétua exposição à vigilância, inexistindo alternativas regulatórias viáveis para estancar ou amenizar ou eventuais efeitos sociais.

Portanto, após a análise dos dados concernentes a União e ao Estado de Santa Catarina, pode-se confirmar a hipótese de que a Copa do Mundo de 2014 colocou a questão da vigilância de espaços urbanos em evidência e, após sua realização, observou-se a tendência dos órgãos de 
segurança pública na incorporação de novas tecnologias, notadamente os drones, os quais são empregados sem qualquer regulação ou política pública clara. Chama à atenção o significativo número de equipamentos adquiridos pelas corporações policiais catarinenses, que, proporcionalmente, demonstram maior interesse na adoção de drones em atividades de inteligência do que as próprias Forças Armadas, sugerindo que o Brasil se preocupa mais com os "inimigos internos" do que externos.

Além disso, nota-se que a utilização de drones no Brasil ultrapassa a própria questão da legitimidade quanto ao emprego em atividades policiais em centros urbanos, porquanto tratase de uma tecnologia de poder que naturaliza a violência, aumenta o controle e traz para o contexto urbano a lógica da guerra, e que vem se espalhando rapidamente graças à racionalidade neoliberal que universaliza bens e serviços.

A própria recusa de informações claras sobre a existência e utilização de drones nas atividades da Polícia Federal sugere que os brasileiros também estão sendo submetidos a vigilância permanente ou, pelo menos, que os órgãos de segurança pública importaram a lógica do "inimigo interno", reconhecendo a cidade como um ambiente onde trava-se um conflito permanente contra um "inimigo" indefinido e latente que pode se esconder em qualquer lugar. E, inclusive, a simples divulgação de informações genéricas e abstratas à pesquisadores poderia colocar em jogo a "segurança nacional".

\section{REFERÊNCIAS}

BRASIL. Serviço Eletrônico do Sistema de Informação ao Cidadão da Controladoria Geral da União. Acesso em: 20 mai. 2018. Disponível em: <https://esic.cgu.gov.br/sistema/site/index.aspx>.

BRASIL. Boletim do Exército. n. ${ }^{\mathbf{0}}$ 39/2014, de 26 de setembro de 2014. Acesso em: 21 mai. 2018.

<http://www.sgex.eb.mil.br/sistemas/be/copiar.php?codarquivo=1302\&act=bre>.

CHAMAYOU, Grégoire. Teoria do drone. Trad. Célia Euvaldo. São Paulo: Cosac Naify, 2015.

CLARKE, Roger. The regulation of civilian drones' impacts on behavioural privacy, Computer Law \& Security Review, v. 30, n. 3, 2014, pp. 286-305. Acesso em: 20 mai. 2018. Disponível em: <https://doi.org/10.1016/j.clsr.2014.03.005>. 
CLARKE, Roger. Understanding the drone epidemic. Computer Law \& Security Review, v. 30, n. 3, 2014, pp. 230-246. Acesso em: 20 mai. 2018. Disponível em: <https://doi.org/10.1016/j.clsr.2014.03.002>.

CLARKE, Roger. What drones inherit from their ancestors. Computer Law \& Security Review, v. 30, n. 3, 2014, pp. 247-262. Acesso em: 20 mai. 2018. Disponível em: <https://doi.org/10.1016/j.clsr.2014.03.006>.

CLARKE, Roger; MOSES, Lyria Bennett. The regulation of civilian drones' impacts on public safety. Computer Law \& Security Review, v. 30, n. 3, 2014, pp. 263-285. Acesso em: 20 mai. 2018. Disponível: <https://doi.org/10.1016/j.clsr.2014.03.007>.

COMANDO DA AERONÁUTICA. [mensagem pessoal]. Mensagem recebida pelo autor em 3 mai. 2018.

COMANDO DA MARINHA. [mensagem pessoal]. Mensagem recebida pelo autor em 9 mai. 2018.

COMANDO DO EXÉRCITO [mensagem pessoal]. Mensagem recebida pelo autor em 11 mai. 2018.

DEPARTAMENTO DE POLÍCIA FEDERAL [mensagem pessoal] Mensagem recebida pelo autor em 7 jun. 2018.

DEPARTAMENTO DE POLÍCIA RODOVIÁRIA FEDERAL [mensagem pessoal] Mensagem recebida pelo autor em 11 mai. 2018.

ESTADO DE SANTA CATARINA. [mensagem pessoal]. Mensagem recebida pelo autor em 8 jun. 2018.

ESTADO DE SANTA CATARINA. [mensagem pessoal]. Mensagem recebida pelo autor em 14 mai. 2018.

ESTADO DE SANTA CATARINA. Ouvidoria Geral do Estado de Santa Catarina. Acesso em: 21 mai. 2018. Disponível em: <http://www.ouvidoria.sc.gov.br/cidadao/>.

FORÇA AÉREA BRASILEIRA. Hermes 900 reforça capacidade operacional da FAB no reconhecimento eletrônico. $2014 . \quad$ Disponível em: $<$ http://www.fab.mil.br/noticias/mostra/18093/REAPARELHAMENTO-\%E2\%80\%93Hermes-900-refor\%C3\%A7a-capacidade-operacional-da-FAB-no-reconhecimentoeletr\%C3\%B4nico>. Acesso em 13 mai. 2018.

FOUCAULT, M. A governamentalidade. In: FOUCAULT, M. Microfísica do poder. Rio de Janeiro: Graal, 1978. pp. 277-293. 
GLOBAL SECURITY. Angel Fire. Disponível em: <https://www.globalsecurity.org/intell/systems/angel-fire.htm>. Acesso em: 08 set. 2018.

HOBSBAWN, Eric. Era dos extremos. Trad. Marcos Santarrita. São Paulo:Companhia das Letras, 1995.

MATE, Reyes. Meia-noite na história - Comentários às teses de Walter Benjamin. Trad. Nélio Schneider. São Leopoldo: Unisinos, 2011.

NEOCLEOUS, M., Air power as police power. In: Environment and Planning D: Society and Space, 2013, v. 31, p. 588. Acesso em: 23 mai. 2018. <Disponível em: doi:10.1068/d19212>.

NEOCLEOUS, M., Air power as police power. In: Environment and Planning D: Society and Space, 2013, v. 31, p. 589. Acesso em: 23 mai. 2018. <Disponível em: doi:10.1068/d19212>.

PAULUS, Daniel. Polícia Civil usa drone em operação para prender suspeitos de tráfico no Meio-Oeste. Publicado em: 5 set. 2013. Acesso em: 20 mai. 2018. Disponível em: $<$ https://ndonline.com.br/oeste/noticias/policia-civil-usa-drone-em-operacao-para-prendertraficantes-no-meio-oeste>.

PERSISTENT SURVEILLANCE SYSTEMS. PSS Law Enforcement Services. Acesso em: 21 mai. 2018. Disponível em: <https://www.pss-1.com/law-enforcement-support>.

SALLES, Eduardo B. C. Corporações transnacionais: novos atores e novos poderes. Porto Alegre, RS: Editora Fi, 2018.

VOLOVELSKY, Uri. Civilian uses of unmanned aerial vehicles and the threat to the right to privacy - An Israeli case study, Computer Law \& Security Review, v. 30, n. 3, 2014, pp. 306320, Acesso em: 20 mai. 2018. Disponível em: 〈https://doi.org/10.1016/j.clsr.2014.03.008>.

WIKILEAKS. Collateral murder. Disponível em: <https://collateralmurder.wikileaks.org/>. Acesso em: 13 de jul. 2018.

WYSS INSTITUTE. Autonomous Flying Microrobots (RoboBees). Disponível em: $<$ https://wyss.harvard.edu/technology/autonomous-flying-microrobots-robobees/>. Acesso em: 13 de jul. 2018. 